\title{
LA CIENCIAS SOCIALES Y LA INVENCIÓN DEL TERCER MUNDO: A PROPÓSITO DE LA OBRA ACADÉMICA DE ORLANDO FALS BORDA (I) ${ }^{1}$
}

\author{
Dr. Javier Guerrero Barón ${ }^{2}$ \\ Universidad Pedagógica y Tecnológica de Colombia \\ Doctorado en Ciencias de la Educación - RUDECOLOMBIA \\ jguerrer99@hotmail.com \\ Dra. Bárbara García Sánchez ${ }^{3}$ \\ Universidad Distrital \\ Grupo de Investigación HISULA-SHELA \\ barbaragarciasanchez@yahoo.com
}

Recepción: 7/07/2009

Evaluación: 7/07/2009

Aceptación: 10/07/2009

Artículo de Reflexión

\section{RESUMEN}

La vida y obra de Orlando Fals Borda lo presenta como uno de los grandes de las ciencias sociales de América Latina. Este escrito pretende resaltar algunos aspectos de su trayectoria intelectual como fundador en 1959 de la primera facultad de Sociología en Colombia, coautor del primer estudio empírico sobre la Violencia en Colombia (1962-1963), Se le atribuye el diseño y la creación de la red social colombiana más extensa, las juntas de acción comunal; Se le reconoce como uno de los sistematizadores y divulgadores más destacados de la Investigación Acción Participativa, -IAP-; Autor

\footnotetext{
1 El presente artículo recoge aspectos de una publicación mayor, actualmente inédita.

2 Sociólogo, Magíster y Doctor en Historia, egresado de la Universidad Nacional de Colombia y profesor titular de la Escuela de Ciencias Sociales de la Universidad Pedagógica y Tecnológica de Colombia e investigador del grupo Historia y Prospectiva de la Universidad Latinoamericana HISULA.

3 Socióloga, Magíster en Sociología y Doctora en Ciencias de la Educación. Profesora del Doctorado en Ciencias de la Educación de la Universidad Distrital Francisco José de Caldas. Grupo de investigaciones "Formación de Educadores".
} 
de numerosos libros y estudios académicos, se auto inscribe indudablemente en la categoría de los "intelectuales", reconocido por las comunidades de sociólogos, antropólogos e historiadores como uno de ellos. Proponemos hacer una periodización de su obra intelectual en cinco grandes etapas: 1) La fundamentación teórica, 19531964.2) La ruptura de los paradigmas positivistas, 1964-1968; 3) De la conciencia transformadora al compromiso revolucionario 1968-1978;4) La IAP y la ciencia al servicio del cambio y la emancipación de los sujetos investigados: 1978-1991;5) La revolución democrática y reordenamiento de la nación de 1991 hasta su muerte en el 2008. En la presente entrega vamos a hacer una aproximación provisional de las dos primeras etapas.

Palabras clave: Sociología Latinoamericana; Ciencias Sociales-innovación; Acción Comunal; Investigación Acción Participativa (IAP); Orlando Fals Borda; Sociología-Compromiso; Sociología-Liberación; Tercer mundismo; Tercer Mundo.

\title{
SOCIAL SCIENCES AND THE THIRD WORLD INVENSION: A PURPOSE OF ORLANDO FALS BORDA'S ACADEMIC WORK (I)
}

\author{
Dr. Javier Guerrero Barón \\ Universidad Pedagógica y Tecnológica de Colombia \\ Doctorado en Ciencias de la Educación - RUDECOLOMBIA \\ jguerrer99@hotmail.com \\ Dra. Bárbara García Sánchez \\ Universidad Distrital \\ HISULA-SHELA Reseach Group \\ barbaragarciasanchez@yahoo.com
}

\begin{abstract}
Life and work of Orlando Fals Borda presents him as one of the most important author of Social Sciences of Latin America. This article pretends to highlight some of the aspects of his intellectual life as founder of the first Faculty of Sociology in Colombia (1959) and as coauthor of the first empirical research on violence in Colombia (19621963). They attribute to him the design and creation of the most extensive social net of participation in Colombia, the Juntas de Acción Communal. He is recognized as one of the greatest systematizer and populariser of the Participatory Action-Research (Investigación Acción Partiipativa). As author of many books and researches he
\end{abstract}


inscribed himself in the "intellectual" category, been recognized by sociologist, anthropologist and historians as one of them. We propose a periodization of his intellectual work in five major stages. (1) The theoretical foundation, from 1953 to 1964. (2) The breaking-off with the positivist paradigm, from 1964 to 1968. (3) From the transformer consciousness to the revolutionary commitment, from 1968 to 1978. (4) The Participatory Action-Research (IAP, because its abbreviation in Spanish) and science for change and emancipation of the investigated person, from 1978 to 1991. (5) The democratic revolution and the reordering of the Colombian nation from 1991 until his death in 2008. In this paper we are going to provide a tentative vision of the first two stages.

Key words: Latin American Sociology, Social Science \& Innovation; Communal Action, Participatory Action Research (PAR), Orlando Fals Borda; SociologyCommitment; Liberation Sociology, Third World.

\section{INTRODUCCIÓN}

Después de su muerte el 12 de agosto de 2008, la biografía de Orlando Fals Borda habla de él como uno de los grandes de las Ciencias Sociales de América Latina, o al menos así lo muestran las reseñas de su vida y obra. Este escrito pretende resaltar algunos aspectos de la trayectoria intelectual de unos de los hombres destacados de las Ciencias Sociales en la segunda mitad del siglo XX, uniéndonos al reconocimiento que otros colegas le han hecho. Dos tesis pretendemos desarrollar: La primera, que Fals es uno de los fundadores de la idea del Tercer Mundo desde la sociología y, la segunda, que su obra, bastante extensa y polémica por cierto, constituyó una ruptura con los paradigmas positivistas dominantes.

\section{Un Activista de las Ciencias Sociales}

En el campo de la investigación social son pocos los colombianos que sobresalen en el plano internacional. Fundador en 1959 de la primera facultad de Sociología en Colombia, coautor con Eduardo Umaña Luna y Germán Guzmán Campos del libro, que es reconocido como el estudio social que más impacto ha tenido sobre la sociedad colombiana y que ha sido comparado como "la comisión de la verdad", de la época más difícil de la historia colombiana del siglo XX y que ocasionó aproximadamente 300.000 muertes: la Violencia en Colombia (1962-1964)4. Se le atribuye el diseño y la creación de la red social más extensa en la base de la pirámide social y que ha jugado un papel fundamental en la formulación de proyectos de desarrollo: las juntas de acción comunal. Anivel mundial se le reconoce como uno de los sistematizadores y divulgadores más destacados del que es quizás el aporte más importante de América Latina a las

4 FALS, Orlando, GUZMÁN, Germán, UMAÑA LUNA, Eduardo. (1962) La violencia en Colombia, Bogotá, Tercer Mundo-Universidad Nacional, (Reimpresión en Bogotá, Editorial Iqueima, 1963). 
ciencias sociales contemporáneas: La Investigación Acción Participativa, -IAP.Luchador incansable, pensador alternativo, autor de numerosos libros y estudios académicos, sin duda se erige como una de las figuras más reconocidas de las ciencias sociales y se auto inscribe indudablemente en la categoría de los "intelectuales". ${ }^{5}$ Recibió importantes reconocimientos por parte de organizaciones europeas y norteamericanas, fue profesor visitante de varias Universidades y autor de innumerables libros y ensayos que tuvieron notoria influencia en varias generaciones de estudiosos de las ciencias sociales, más allá de la Sociología y reconocido por las comunidades de antropólogos e historiadores como uno de ellos.

Desde los años sesenta Orlando Fals Borda es uno de los científicos que hizo presencia en los foros y publicaciones internacionales. De su prolífica obra académica se han dicho muchas cosas y son varios los artículos e inclusive libros sobre su obra ininterrumpida desde 1953. Son más de 55 años de vida profesional e intelectual que muy pocas personas pueden mostrar, desde su primer artículo sobre la evolución del vestido campesino, que junto con una trilogía de artículos sobre una de sus obsesiones: el problema de la tierra. Incursionó También en el campo de la Historia, la Antropología, la política e incluso en la geografía, ésta última al proponer un nuevo ordenamiento territorial del país en calidad de miembro de la Asamblea Nacional Constituyente de 1991, cuando propuso la Comisión de Ordenamiento Territorial como instrumento fundamental para la administración de los recursos, del poder y de los conflictos de manera más equitativa y racional. Al final de su vida terminó siendo uno de los promotores del proyecto político de la izquierda democrática que busca salidas civilizadas a largo conflicto armado.

En este trabajo proponemos hacer una periodización de su obra intelectual en cinco grandes etapas:

1-La fundamentación teórica, 1953-1964.

2-La ruptura de los paradigmas positivistas, 1962-1968;

3-De la conciencia transformadora al compromiso revolucionario 1968-1978;

4-La IAP y la ciencia al servicio del cambio y la emancipación de los sujetos investigados: 1978-1991;

\footnotetext{
5 Es quizás el único caso estudiado que hizo tránsito por todas las cuatro categorías que nos hemos planteado en un estudio sobre los docentes universitarios. La idea está siendo desarrollada por los autores en un proyecto de investigación en curso titulado "EL Profesor Universitario y la Actitud Intelectual ante la Guerra-1948-2002". Retomamos provisionalmente la periodización desarrollada por el historiador Gonzalo Sánchez, quien se plantea cuatro categorías de intelectuales, a manera de etapas históricas sucesivas o "momentos y modalidades": a) Los Intelectuales Maestros, 1940-1959 b)Los Intelectuales críticocontestatarios o proféticos 1960-1980 c) Los Intelectuales Ciudadanos o Intelectuales para la Democracia, 1980-1990 y d) Los Intelectuales Mediadores 1990-2002 que la hemos definido como intelectuales para la paz la transformación de la guerra. SÁNCHEZ GÓMEZ, Gonzalo. (2000): El compromiso social y político de los intelectuales. En: Revista "Pensamiento y Acción". Revista Internacional de la Universidad Pedagógica y Tecnológica de Colombia. No. 10, p. 5-16. Intervención con motivo del otorgamiento de la Diskin Memorial Lectureship por la Latin American Studies Association y Oxfam America, "For the Integration of Scholarship and Activism", Miami.
} 
5-La revolución democrática y reordenamiento de la nación de 1991 hasta su muerte en el 2008.

La Fundamentación Teórica y la Investigación de Campo: De la primera época sus trabajos más significativos fueron "Campesinos de los Andes" $(1955)^{6}$, su tesis magistral en Minnesota University y "El Hombre y la Tierra en Boyacá" (1957), su disertación doctoral en la Universidad de Florida, muy bien recibidos en los círculos académicos. Inició su camino simultáneamente como político, en calidad de concejal del municipio de Chocontá, mientras hacía su trabajo de campo. Formado en las vertientes del funcionalismo sociológico de las escuelas norteamericanas, muchos de sus trabajos de esta época se confunden con los rituales etnográficos de la antropología adquiriendo cada vez un mayor compromiso ético y político con las comunidades campesinas. Estos primeros trabajos lo sumergieron en el mundo rural colombiano de los estertores finales de la Violencia, en frecuentes preocupaciones frente al gamonalismo terrateniente que se entrelazaba con las dirigencias de los partidos tradicionales, fenómeno que poco a poco fue entendiendo como el principal obstáculo de la transformación del país.

Sin duda, el trabajo más representativo de este período es "El Hombre y la tierra en Boyacá" (1957). Han transcurrido más de 50 años $^{7}$ desde cuando fue escrito este libro si no el primero- uno de los primeros tratados de sociología agraria guiados con los nuevos paradigmas de las teorías sociales del siglo XX, y quizá uno de los textos fundacionales de una corriente de estudios agrarios latinoamericanos dedicados a las sociedades minifundistas, escrito con el propósito de abrir el debate sobre la necesidad de una reforma agraria, que -hoy más que nunca- es un requisito para que la guerra pueda llegar a su fin, siendo Colombia uno de los pocos países donde fracasó todo intento de redistribución equitativa de la propiedad rural y donde, por el contrario, varias oleadas de violencia con sus consecuentes contra-reformas agrarias han sucedido en ese lapso.

Boyacá, La Industrialización y la Ilusión del Progreso: El autor, hacia 1950, percibía el preludio del «progreso» hacia el modelo de desarrollo industrial que se anunciaba en esos tiempos con la entrada en funcionamiento de la Siderúrgica de Paz del Río y con la euforia inversionista en vías de comunicación, electrificación y transporte, que se generó durante el gobierno del general Gustavo Rojas Pinilla, oriundo de Boyacá y que por este motivo privilegió la inversión en su departamento natal. En consecuencia, sin desconocer el peso de la tradición, la cual estudia desde una dimensión

\footnotetext{
6 FALS BORDA, Orlando. (1961): Peasant Society in the Colombian Andes: A sociological study of Saucio, Gainesville, University of Florida Press. Edición castellana con el título de Campesinos de los Andes, Bogotá, Universidad Nacional-Facultad de Sociología.

7 FALS BORDA, Orlando. (1955): El hombre y la tierra en Boyacá: Bases sociológicas e Históricas para una Reforma Agraria. Bogotá. Ediciones Colombianas, (Cuarta ed. Tunja, UPTC, 2006). En mayo de 2007 en un sencillo acto organizado por la UPTC en la Feria Internacional del Libro de Bogotá se conmemoraron los 50 años de la publicación de su primera edición.
} 
histórica de larga duración en el sentido broudeliano, desde las tradiciones precolombinas, plantea como hipótesis central que Boyacá por esos años se encontraba en una profunda transición entre la sociedad tradicional y la sociedad moderna y que estas transformaciones irían a impactar lo que hoy llamaríamos el modelo de desarrollo hacia un proceso de industrialización.

Como él mismo lo narra, el estudio se realizó recorriendo en "jeep" los caminos intransitables de Boyacá, en el momento en que la vieja Violencia agraria en muchas regiones se cubría con el manto del también agudo conflicto bipartidista y se transformaba en guerra de contrainsurgencia tras una efimera entrega de armas lograda luego de la firma de la paz con los guerrilleros del llano y en momentos en que se iniciaba la ofensiva sobre el Sumapaz, con la llamada "Guerra de Villarrica", que dio origen en Colombia a las guerrillas comunistas y cuando marcaba el comienzo del denominado bandolerismo endémico. Es así como de manera profética Fals Borda señala que si Colombia no resuelve el problema de su reforma agraria la sangrienta conquista de la tierra continuará. Y sentencia lapidariamente: "Así como ha sucedido en otras partes, es casi ineludible que los problemas que surgen de la ecuación Hombre-Tierra se conviertan para Colombia en $l$ a en la enfermedad Social del Siglo XX', como en efecto ha sucedido y amenaza en convertirse en el núcleo del problema agrario irresuelto en el siglo XXI. ${ }^{8}$

La Acción Comunal: Una Alternativa a la Violencia: Pero el problema para Fals no era el de simplemente estudiar la realidad. Había en él desde su juventud un afán de transformar que lo llevó desde este primer trabajo a buscar la "utilidad" de sus estudios. Es así como se lanza a la creación de su primer laboratorio social para la solución de los problemas de las comunidades. En junio de 1957 en la Vereda de Saucío en el municipio de Chocontá, a donde había llegado a hacer los estudios ambientales y sociales de las obras de la Represa del Sisga, fundó con un grupo de campesinos la primera Junta de Acción Comunal. Posteriormente en los sesenta trabajó con el cura sociólogo Camilo Torres y con María Cristina Salazar, su esposa, en el diseño de una propuesta de programas sociales para la post-violencia para reconstruir el tejido social, propuesta que fue acogida y cooptada por el Ministerio de Gobierno del primer gobierno del Frente Nacional, por lo que se le atribuye el diseño de la red social más extensa en la base de la pirámide social y que ha jugado un papel fundamental en la formulación de proyectos de desarrollo de los sectores populares. De esta manera contribuyó con sus estudios a la transformación de las Juntas de Mejoras, tradicionales de las ciudades y los directorios veredales y juntas de vecinos, en las modernas Juntas de Acción Comunal que ayudó a difundir desde su efímero paso por el Ministerio de Agricultura y a través de la recientemente fundada primera Facultad de Sociología, ${ }^{9}$ hasta el punto de que

\footnotetext{
8 Así lo ratifica el reciente trabajo de uno de sus colegas y contertulios en la etapa del IEPRI: REYES, Alejandro. (2009): Guerreros y Campesinos. El despojo de la tierra en Colombia. Bogotá, Editorial Norma.

9 Con Camilo Torres, María Cistina Salazar y algunos de sus estudiantes crearon el Movimiento Universitario de Promoción Comunal (MUNIPROC), para el desarrollo de la acción social en barrios populares y obreros de Bogotá, como el barrio Tunjuelito, en los albores de lo que sería posteriormente la Teología de la Liberación, donde recibieron el apoyo entusiasta del cura español Domingo Laín quien murió, años después del cura sociólogo, también en las filas del ELN.
} 
podríamos afirmar que no existe barrio o vereda incluso de estratos medios y altos que no tenga un organismo de este tipo, aún en sitios apartados. Sin embargo, al mismo tiempo reconocía que estos organismos comunitarios fueron usados también por los partidos tradicionales para fortalecerse y cooptar a sus dirigentes para sus estrategias electorales y clientelistas desvirtuando los principios para los cuales fueron fundados..$^{10}$ No cabe duda que este es uno de los grandes aportes de Fals a la convivencia colombiana, primero en las veredas y los pueblos y luego en los barrios populares.

La Violencia en Colombia: Dos Tomos de la Historia de la Ignominia: Había fundado, como ya se dijo, en 1959 la Facultad de Sociología en la Universidad Nacional y transcurría por aquellos días el primer gobierno del Frente nacional, y por iniciativa del presidente Alberto Lleras Camargo se constituyó la "Comisión para el Estudio de las Causas de la Violencia", especie de "Comisión de la Verdad" a cerca de la tormenta social y política que azotó a Colombia a partir de 1946, oportunidad que se prestó para que el joven decano de Sociología llamara a monseñor Germán Guzmán Campo y a dos de sus profesores, el cura sociólogo Camilo Torres y el connotado jurista Eduardo Umaña Luna, a integrar un equipo de investigación sobre "sus causas", para que fueran divulgado en un diagnóstico en profundidad sobre esos sucesos tan dolorosos para el país. ${ }^{11}$ De este trabajo se publicaron los dos tomos de uno de los libros más polémicos de la historia reciente del país. ${ }^{12}$ Durante el Frente Nacional se pretendió tender un manto de olvido. Era un pacto de "perdón y olvido", aunque lamentablemente la figura del "perdón y olvido" en la realidad no existe como tal y menos en la historia. Se trata de una ficción jurídica que en la vida real es imposible. Puede ser, y eso habría que demostrarlo, que haya existido perdón entre liberales y conservadores. Pero lo que no podía existir era el olvido de sucesos tan notorios y que afectaron a tantos colombianos. El país no podrá olvidar estos importantes acontecimientos de su historia reciente, por dolorosos que ellos sean, a no ser en virtud de un acto de control de la información y de la memoria colectiva, como hasta ahora ha sucedido.

\footnotetext{
10 El 7 de junio de 2008, dos meses antes de su muerte, en la vereda de Saucío en Chocontá algunos de sus amigos lo acompañamos al último homenaje que recibió en vida cuando las juntas de acción comunal de esta zona de Cundinamarca le rindieron un reconocimiento sentido a la labor de un trabajador social. De este acto social en el que no estuvo presente ninguna autoridad departamental ni nacional, ni siquiera la gran prensa, existe testimonio filmico recopilado por el licenciado Luvin Camargo, profesor de Ciencias Sociales de ese municipio e principal impulsor del este acto.

11 Camilo Torres no pudo escribir su informe y pronto se vio marginado del equipo de trabajo, dado que se dedicara al intenso trabajo comunal y barrial, por lo cual el Cardenal de Bogotá, Luis Concha Córdoba, le pareció excesivo su activismo y le pidió la renuncia a sus actividades en la Universidad Nacional, encomendándole en 1962 la Parroquia de Veracruz. No obstante, en 1963 en el marco del Primer Congreso Nacional de Sociología, celebrado en Bogotá, presentó su estudio "La violencia y los cambios socioculturales en las áreas rurales colombianas", el cual era su contribución al libro colectivo. Ver: TORRES, Camilo. (1966): "La violencia y los cambios socioculturales en las áreas rurales colombianas", En: Revista La Gaceta, año III, nº 16-17, sept.-oct.-nov.-dic. Bogotá. Colombia.

12 Retomamos algunas ideas planteadas en la introducción de GUERRERO, Javier. (2007): Los Años del Olvido: Boyacá y los Origenes de la Violencia. Tunja, UPTC.
} 
Este acto de ejercicio de la memoria se constituye, desde nuestro punto de vista, en notorio y valientes aportes a la sociología y a la historia colombiana. Primero, como obra colectiva, segundo como material empírico, la mayor parte aportado por la experiencia de Guzmán, quien como párroco de El Líbano, Tolima, donde de manera directa había conocido las realidades de los pobladores, y con las luces jurídicas y criminológicas de Umaña y la interpretaciones y el apoyo institucional de Fals, lograron construir una de las primeras aproximaciones de las ciencias sociales al problema. Posteriormente numerosos estudios se han basado necesariamente en esta primera visión sistemática de uno de este período dramático de nuestra historia republicana. Reseña así Gonzalo Sánchez el origen de este libro que califica como sin "dudas el primer producto colectivo en las ciencias sociales en el país" y luego sentencia "con él se inicia la historia contemporánea de las ciencias sociales en Colombia":

Golpe de intuición, por consiguiente, del grupo de emisarios de la recién fundada Facultad de Sociología de la Universidad Nacional, Camilo Torres, Orlando Fals Borda (decano de la Facultad), Andrew Pearse (sociólogo británico) y Roberto Pineda Giraldo, que a principios de 1961 se fueron en busca de Guzmán al Líbano. La propuesta era precisa: que se trasladara a Bogotá para que con la cooperación de otros colegas y con base tanto en su experiencia personal en aquella región crucial de la Violencia, como en los materiales que de todo el país se había acumulado en el curso de su labor en la Comisión, elaborara un libro en el ambiente intelectual, crítico e independiente de la Universidad Nacional.... El libro hizo su resonante aparición en julio de 1962 y con él se inicia también en buena medida la historia contemporánea de las ciencias sociales en Colombia. ${ }^{13}$

Las consecuencias de este estudio no se hicieron esperar. Los estigmas hicieron que el apoyo inicial del establecimiento se diluyera y el Departamento de Sociología en adelante fuera visto con desconfianza no solamente por los académicos sino por los poderes políticos, dentro y fuera de la Universidad. Aunque esta página abre un camino importante en la obra sociológica del país, también se convierte en un problema, especialmente para la tranquilidad de sus autores.

La Sociología y el Problema Del Desarrollo: La Crisis de la Facultad: Pero el impulso de Fals Borda como hombre de las ciencias humanas no quedaba allí. En 1964 fundaba, lleno del optimismo que caracterizó esa década, uno de los primeros postgrados del país, "Programa Latinoamericano de Estudios para el Desarrollo", PLEDES, con el auspicio de la Universidad de Madison, y el apoyo de destacados gestores de la teorías del Desarrollo y de la Dependencia, en boga en ese momento, para que sus estudiantes egresados pudieran entrar en la era de los estudios avanzados de gran utilidad para el país. Pero pronto las contradicciones del mundo académico convertirían el ambiente de la nueva facultad en uno de los capítulos difíciles de su vida académica y personal: las contradicciones políticas y personales se agudizaron e hicieron que esta rica

13 SANCHEZ, Gonzalo. (1999): Reseña de "La Violencia en Colombia" En: Revista Credencial Historia., No 110. Bogotá. 
experiencia feneciera en 1969, tras aportar al país tan solo una promoción de egresados, en tanto que Fals y el país intelectual en general, entraba en profunda crisis sobre sus convicciones sobre la validez del tipo de estudios predominantes en esos tiempos. El debate sobre la cuestión de la neutralidad valorativa de la sociología "científica" desató el nudo de esta contradicción. Así reseña este episodio uno de sus protagonistas:

Estos fueron años de controversias teóricas y metodológicas. Quizá la más significativa fue la que sostuvo con el sociólogo uruguayo Aldo Solari sobre la objetividad, el compromiso y la sociología libre de valores. En este intercambio Fals insistió en que la elección de temas alejados de los problemas más acuciantes de la sociedad muestra hacia dónde se inclina el cientifico y qué valores lo asisten. Si persiste en su alejamiento y en el desconocimiento de las tensiones de la sociedad contemporánea, "no sólo se descubre la orientación conservadora y reaccionaria del científico, sino que se echa por tierra la justificación histórica de la sociología como ciencia de la crisis". La querella de Fals era una manifestación endógena de las discusiones sobre la crisis de la sociología occidental que ocupaba la atención de los sociólogos europeos y estadounidenses durante aquellos años, caracterizada por la quiebra del funcionalismo como marco de referencia hegemónico, que tuvo su expresión más acabada en el sonado libro de Alvin Gouldner, La crisis de la sociología occidental (1970)14. "Hoy teorizamos entre el estruendo de las armas de fuego [la guerra de Vietnam estaba en la cúspide]. El viejo orden tiene clavadas en su piel las picas de cien rebeliones", escribió Gouldner con vigor en la primera página de su obra para llamar la atención de los intelectuales renuentes a tomar conciencia de los problemas de su tiempo. ${ }^{15}$

La confrontación académica sobre la cuestión de los valores y la neutralidad, que se particularizó en una polémica con el prestigioso académico uruguayo Aldo Solari y que se plasmó en sendas publicaciones, fue el catalizador de una polarización más $a^{a m p l i a}{ }^{16}$, en la que influyó la ortodoxia frente a lo que ya venía planteando desde "Campesinos de los Andes" 1955, libro que tiene intenciones "no científicas" ocultas que al autor reconoce, cuando afirma en la edición española de 1961 lo que realmente buscaba en este trabajo: "quería constatar si lo que se decía del hombre rural colombiano era cierto, si merecía su suerte como despreciable siervo de la gleba, si su estupidez aparente o 'melancolía indígena' era atávica, si su destino como ente sub-humano era inevitable". Luego agrega que no hay que buscar en ese estudio "un trabajo de campo encaminado generalmente a poner a prueba algunas hipótesis preconcebidas", afirma por el contrario que "Saucío fue estudiado sin ánimo de poner a prueba teorías concretas", para "construir puentes afectivos y sociales entre el investigador y la comunidad".

\footnotetext{
${ }^{14}$ GOULDNER, Alvin W. (1979): La Crisis de la Sociología Occidental. Editorial Amorrortu, Buenos Aires.

15 CATAÑO, Gonzalo. (2008): Orlando Fals Borda, sociólogo del compromiso, en Revista de Economía Institucional, vol. 10, $n .^{\circ} 19$, segundo semestre, pp. 79-98.

16 FALS BORDA., Orlando. (1969) "La crisis social y la orientación sociológica: una réplica", Revista Aportes 13, pp. 62-76. Solari, A. "Algunas reflexiones sobre el problema de los valores, la objetividad y el compromiso en las ciencias sociales", Revista Aportes 13, pp. 6-14.
} 
Pronto los científicos de las universidades se percatarían de estos intereses "no científicos" de este investigador y lo pondrían en el banquillo de los acusados.

La Ruptura con los Paradigmas Positivistas: El debate sobre la crisis mundial de la Sociología desemboca directamente en la que hemos llamado la segunda época de su obra intelectual, muy importante en el desarrollo de su pensamiento y quizás el principal suceso que lo llevó a una radical ruptura con la vida académica; de ella surge su enfrentamiento a los paradigmas de positivismo y a lo que el llamaba "la burocracia académica". Vendría entonces uno de los momentos más difíciles para su proyecto de vida y para su proyecto académico de la facultad que entraría en una profunda reforma curricular, paralela a la reforma general de la Universidad Nacional. Grupos radicalizados de colegas y estudiantes de izquierda, lo acusan de ser agente de la CIA y de las multinacionales y sobre todo, en un acto de dogmatismo e intolerancia, de no ser marxista, marcado existencialmente por serios replanteamientos intelectuales frente a la que consideraba "esterilidad de la academia" se da la situación que lo lleva a decidir su retiro de la Universidad Nacional el cual se daría por varios lustros hasta la creación del IEPRI en 1985 cuando regresa como investigador al lado de Alfredo Vásquez Carrisoza, Álvaro Tirado Mejía, entre otros. Pero su ruptura con las nociones "científicas" dominantes en la sociología era el comienzo de un camino sin retorno, lleno de situaciones difíciles e incomprensiones.

El Problema de la Praxis Científica y Revolucionaria: Esta experiencia desata su primera ruptura epistemológica con el positivismo sociológico de su primera juventud. Enfrentado a la escuela pontificia fundada en 1960 por quien luego sería su esposa, primera socióloga mujer en colombia, María Cristina Salazar, atacado permanentemente por las prevenciones que desataba su condición de no católico y por su participación en la Comisión y en el libro de la Violencia, tuvo un primer acercamiento a través de este grupo de sociólogos católicos que incluía a Camilo Torres, con la experiencia indirecta de los sacerdotes obreros de París y con la teología de la liberación, que a su vez lo colocó de frente a las efervescentes tesis del marxismo sesentino, cuyas polémicas, como hemos dicho, no pocas veces intolerantes y sectarias, le hicieron abandonar en 1968 la universidad durante 18 años, como diría el, "para volver a pensar la sociología" lejos del ambiente metafísico de los debates interminables, la poca investigación y de cara a las urgencias del país real. Esta transición lo transforma en un activista social que a partir de sus investigaciones se propone una mayor incidencia transformadora de las realidades y los problemas de la sociedad. La muerte de Camilo en las filas de la guerrilla, luego la del "Ché", habría transformado la experiencia existencial de sus contertulios académicos. Muchos de ellos, ya alineados en los escepticismos de la izquierda universitaria y tocados por la figura carismática del padre Camilo, y envueltos en la atmósfera contestataria y rebelde de esos tiempos, convencieron a Fals de la esterilidad de la etapa de los estudios empíricos ligados al positivismo y a las encuestas cuantitativas y lo lanzan por el camino de los replanteamientos.

Abre una nueva etapa su ensayo "Subversión y Cambio Social", (1968) en el que demostró su capacidad de autocrítica pues era la edición corregida de "La Subversión 
en Colombia" 1967, libro que había sido muy criticado en círculos académicos y en la que corrigió muchas de las señaladas debilidades por sus amigos y críticos. Luego de sus grandes éxitos académicos, las transiciones teóricas, epistemológicas y sobre todo políticas que lo inclinaban a tratar de entender el fenómeno de la subversión, este trabajo produciría incomprensión entre sus colegas próximos y extranjeros. Así lo reseña uno de sus biógrafos:

El libro sobre la subversión, un volumen de cerca de 300 páginas, fue redactado con premura y casi sobre los acontecimientos políticos del año de su publicación. Estaba escrito en un lenguaje descuidado y el frecuente uso de conceptos y de definiciones hacía que su prosa cayera en una pesada jerga de dificil alcance para el lector no iniciado. ${ }^{17}$

Indudablemente no era este su mejor momento, pero esta situación no lo doblegaría pues el opúsculo final de la segunda versión se convirtió en best seller, principalmente entre los jóvenes, publicado por como Las revoluciones inconclusas de América Latina, (1968), el cual fue contemporáneo y de laguna forma visionario sobre el cisma de los jóvenes que se expresaba en Tlatelolco, o en la revolución de mayo del 68 en París, o en la Primavera de Praga, lo que animó a las editoriales a publicar el libro original completo en inglés, lo cual volvió a colocarlo entre los grandes latinoamericanos en el mundo académico, no sin acres comentarios en muchos ámbitos como lo refleja la reseña de un importante analista científico soviético en uno de los manuales del credo comunista de esos tiempos:

La concepción de Fals Borda, a pesar de su pretensión de originalidad, lleva la impronta de la interpretación elitaria de la revolución. La revolución es concebida como un acto puramente destructivo y externo a la sociedad estable. Sus orígenes están en el ámbito del espíritu y de la conciencia crítica. ${ }^{18}$

No obstante esta distancia descalificadora de los ortodoxos de la doctrina marxista, luego de las dos versiones de su libro "la Subversión", en Colombia y en Latinoamérica Fals fue visto desde entonces como un apóstol de la lucha armada con las consecuencias que eso traería para su vida personal.

\section{El Paradigma del Marxismo y la Construcción de una Ciencia Propia en América Latina}

Roto el encanto del Frente Nacional, decepcionado de su propia obra intelectual y de su creatura académica, la Facultad de Sociología, quebrada la ilusión de una reforma agraria, pues conoció por dentro la institución rectora de este estruendoso fracaso, pues asistía con Camilo Torres a la Junta del INCORA, se refugió en los jardines interiores de su familia recién formada. Comenzaba una vida nueva con la experiencia

\footnotetext{
17 CATAÑO, Gonzalo y FALS BORDA, Orlando. (2008): "Sociólogo del compromiso", en Revista de Economía Institucional, vol. 10, $n .{ }^{\circ} 19$, segundo semestre, pp. 79-98.

18 BURLATSKI, F., dir. (1982): Materialismo histórico, Moscú, Editorial Progreso, p. 337. Citado por Cataño.
} 
de Ginebra, 1968-1970. A su regreso montó dos herramientas organizativas que se convirtieron en su laboratorio social: el grupo de investigaciones "La Rosca" y la editorial "Punta de Lanza" y una fuerte esperanza en América Latina, que se va a ver en sus reflexiones epistemológicas sobre "Ciencia propia y colonialismo intelectual" que abre la publicación de cinco trabajos en 1970, la crítica al reformismo, el cooperativismo, la educación y la organización popular y otros temas que están estrechamente ligados a los problemas agrarios y a las luchas y la educación popular, etapa que llega a su punto culminante con el Simposio Mundial de Cartagena donde publicaría el trabajo que se considera fundador de los principios epistemológicos de la investigación-acción participativa, IAP: "Por la Praxis: Como investigar la realidad para Transformarla" y otros trabajos de importantes académicos del mundo que fueron traducidos a varios idiomas y que a partir de 1978, se podría decir, fundan una corriente de investigación social que inicialmente fue cuestionada y rechazada por numerosos académicos incluso alumnos suyos, pero que poco a poco ganó reconocimiento internacional y por esa vía en el ámbito local.

¿Es posible una sociología de la liberación? La ruptura con los clásicos del funcionalismo y el positivismo era irreversible. Muchas voces criticaron este período de "toma de partido" pretendida por Fals, frente a los temas de la neutralidad de las ciencias. Luego de su tránsito por la universidad y por la investigación, se transforma en un intelectual, en el sentido estricto del término, más que en un académico o un político. Pero su compromiso intelectual no tenía ningún reato en acercarse a un marxismo con un amplio contexto intelectual, a pesar de su formación inicial en el funcionalismo positivista. En una entrevista realizada en el 2002 manifestaba con toda claridad su postura de esos años:

Un intelectual contemporáneo - ese es mi caso- se coloca en una corriente crítica que viene de muy atrás; yo diría que las raíces de mi actitud crítica pueden estar no solo en las lecturas de ciertos clásicos como Erasmo, los enciclopedistas, algunos socialistas del siglo XIX, sino en la rebelión de los intelectuales franceses a partir de la segunda guerra mundial, especialmente Jean Paul Sartre y su concepto de compromiso. Mis orígenes los coloco allí porque ese fue un concepto que luego fue elaborado por Camilo Torres Restrepo y, que tanto impactó a los de mi generación, que trató de demostrarlo con su práctica no solo política sino militar; en esa corriente del compromiso, vemos que aparecieron corrientes de pensamiento que se encontraban sustentadas teóricamente en las escuelas positivistas y racionalistas y tampoco lograron satisfacerse con el marxismo dogmático. Creo que han incidido en mí mucho las lecturas de Gramsci, especialmente "los cuadernos desde la Cárcel", sobre el intelectual orgánico entre otras cosas. Sin embargo, esa rebelión contra las escuelas, incluyendo el marxismo de ese tipo, es decir, dogmático, me fue llevando a un replanteamiento de las metodologías en las ciencias sociales y en los problemas epistemológicos del por qué y para que de las ciencias y de los conocimientos y su relación con el poder establecido. ${ }^{19}$

19 FALS BORDA, Orlando. (2002): Entrevista realizada por Javier Guerrero para la Revista Pensamiento y Acción. Bogotá, 3 de agosto.

Rhela. Vol. 12. Año 2009, pp. $42-61$ 
Sin embargo, valdría la pena profundizar en las características de ese acercamiento epistemológico a un marxismo no dogmático. En la mencionada entrevista dio una respuesta que a nuestra manera de ver es esclarecedora: Ante la pregunta formulada sobre la importancia que le concedía a la última tesis sobre Feuerbach, la idea aquella de que el pensamiento no tiene que contemplar la realidad sino transformarla, en su trayectoria sobre el papel del pensador en la investigación-acción y por qué tanto énfasis en esa idea, respondió en los siguientes términos que son importantes para establecer luego los fundamentos epistemológicos de su nueva postura y de la IAP:

Sí. Esa es la famosa undécima tesis de Marx sobre el pensamiento de Feuerbach y la pongo central por que combina el conocimiento filosófico con la actitud valorativa. O sea, combina el pensamiento y los valores sociales y los pone frente a un espejo, es decir, que son el resultado de la práctica real y Marx tenía toda la razón en exigirles a los filósofos que aterrizaran de esa estratosfera en que usualmente se colocan cuando hablan, refiriéndose a la tradición alemana, pero que entre nosotros mucho del pensamiento no ha pasado de unas expresiones verbales, como una especie de juegos de palabras que se autocomplacen con lo que dicen y con lo que están pensando, pero que no lo traducen a la acción. Eso es central en el modelo de investigación que he venido tratando de hacer y que he impulsado con otros colegas de muchos países.

Los estudiosos de su obra coinciden en la articulación que se dio entre su trabajo comunitario y la expansión de la Teología de la Liberación y su permanente contacto con los seguidores de estas tendencias así como su similitud y contemporaneidad con el pensamiento de Paulo Freire y de otros "socialistas" latinoamericanos. De alguna forma Fals y algunos de sus estudiantes y egresados de la primera década se articularon con una "ola" de pensadores latinoamericanos que convergieron en una crítica argumentada al colonialismo político e intelectual. Eran los inventores, junto con algunas tesis de los marxismos ortodoxos y heterodoxos -porque allí confluye incluso Mao Tse Tung, los teóricos de la CEPAL, europeos como Jean Paul Sartre, Charles Bettelheim y los intelectuales de "Socialismo o Barbarie" quienes convergen eufóricamente en una idea que venía desarrollándose desde Martí y Vasconcelos, que continuaba con Leopoldo Zea y que se relanzó con la Revolución Cubana, con la idea de la Revolución Continental del Che- en una amalgama de intuiciones que se cristalizaban en la noción del "tercer mundo", como la esperanza de la humanidad, donde América Latina era una especie de vanguardia.

Es indudable que esas nociones tenían una alta dosis ideológica y utopía. Había abandonado el territorio firme de la sociología clásica y la más rentable en ese momento: las escuelas positivistas norteamericanas con sus consultorías y encuestas tan demandadas por las entidades públicas y por las empresas multinacionales en los que se refugiaban la mayoría de sus colegas para entrar en las arenas movedizas de la sociología crítica, rechazada por las ortodoxias de las izquierdas y las derechas dominantes en los ambientes universitarios. Algunos de sus críticos señalaban como la pretensión de una ruptura epistemológica no pasó de ser una ruptura ideológica: 
Las ciencias sociales y la invención del mundo

La «ciencia comprometida» surge como ruptura ideológica plegada al humanismo revolucionario de los años sesenta. Corresponde al acertijo y la escogencia entre «ciencia burguesa» y «ciencia proletaria» para ejercer una "praxis» en "toma de posiciones»: de clase e ideológica. A esta época corresponde también la emergencia en Latinoamérica de corrientes academicopolíticas en busca y en beneficio de "las masas»o «sectores populares», como la «pedagogía del oprimido» de Paulo Freire, la crítica a la escuela capitalista y a la neutralidad científica de Tomás Vasconi, la «filosofia latinoamericana» de Leopoldo Zea, y la práctica neo-cristiana «en busca del arca» del cristianismo primitivo denominada «teología de la liberación». En ellas se inscribe una ruptura ideológica de carácter contestatario frente a la agresión y dominación imperial, en cuya gestión se enmaraña en distinciones que pretenden, sin lograrlo, realizar posibles «rupturas epistemológicas» como las mencionadas por Gastón Bachelard. ${ }^{20}$

El camino hacia la IAP por esta corriente de "sociólogos comprometidos" sigue siendo aún hoy muy polémica y poco aceptada en los ambientes académicos. Las resistencias de los cánones de la sociología tradicional le siguen negando estatuto científico a la obra de Fals después de su retiro de la Universidad Nacional. Inclusive se duda del distanciamiento con el positivismo y con su acercamiento al marxismo y muchos de sus planteamientos se miran con ironía:

La ruptura ideológica en el interior de las ciencias sociales no logra instituir una ruptura en la episteme que las constituye. Logra sí enmarañar-las de "praxis política», llevándolas a una situación paradójica en la cual o se convierten en discursividad ideológica o, cuando posteriormente intentan desembarazarse de ella, "retornan a la tierra» del positivismo y la escatología a la manera de una interacción e interrelación Comte-Marx, pero tratando de no mencionar al primero. Escatología como unidad objetiva del discurso sobre el hombre, y positivismo como verdad objetiva definida desde la del objeto, para reterritorializarse en el humanismo antropocéntrico como fundamento de la «investigación-acción participativa. ${ }^{21}$

La verdad es que eran críticas fáciles y sin profundidad que incluso llegaron a caricaturizar sus planteamientos como respuesta a un esfuerzo intelectual que era un proceso, si bien en un principio impreciso, pero que pronto se fue fundamentando, proceso en el que Fals tenía la osadía de dar un debate muy latinoamericano frente a la sociología mundial, como muy pocos hombres de las ciencias sociales del tercer mundo se atrevieron.

La respuesta fue una caricatura que se repitió en muchas de las reseñas de sus textos:

¿Qué queda de la ruptura ideológica? Su contraposición entre «ciencia

\footnotetext{
20 TORRES William. Fals Borda y su Obra. Reseña de Ciencia y Compromiso. Gonzalo Cataño, Comp. En Boletín Cultural y Bibliográfico, Número 12. Volumen XXIV - 1987. Consultado 3-jul-2009. http://www.lablaa.org/blaavirtual/publicacionesbanrep/boletin/ boleti3/boll2/fals.htm

${ }^{21}$ Ibídem.
} 
propia y colonialismo intelectual» no logra desbordar la fundamentación epistémica en la que se construyen y tejen las ciencias humanas. Las mantiene atadas a la bipolaridad del "compromiso» que se puede matizar con la pregunta: "¿con qué clase nos casamos?», y en consecuencia jugar al materi-leri-leró: «¿qué nombre le ponemos?». De las rupturas ideológicas no queda otra cosa que un cambio de coloración en la grafia con tenues variantes de sabor, «descubiertas» hace rato por la etnología, en la recuperación y la activación de la voz en la escritura sociológica de aquellos que no autogestan la escritura. Ahora se escribe «para ellos», pero quienes lo leen seguimos siendo quienes lo escribimos y editamos. Tal vez al escribirlo la voz se desactive, sedentarice y emperece... Estamos ante la paradoja de la «escritura revolucionaria»: entre el mate-rile y la activación e invención del saber.

Críticas que coinciden casi literalmente con los comentarios que escuchamos durante varios lustros por nuestros profesores, imbuidos más que en el marxismo, en la idea fija de los paradigmas weberianos de la neutralidad valorativa. No obstante, otros críticos fueron más profundos y respetuosos con su obra y tomaron en serio su propuesta.

¿Es posible una ciencia propia? Mientras ciertos círculos de la Universidad Nacional lo estigmatizaban como agente del imperialismo, muchos no comprendían el giro Fals estaba dando en esos años. Había iniciado su etapa de Ginebra en 1968 reflexionando sobre el papel de Europa y Estados Unidos en la generación del conocimiento y el papel subalterno de América Latina. Su cercanía a los círculos brasileros, chilenos, argentinos, peruanos y mexicanos le alimentó esta rebeldía contra sus ancestros sociológicos. En 1970 lanza su polémico ensayo, "Ciencia Propia y Colonialismo Intelectual" que agrandaría el sisma con las academias, el que introducía agradeciendo a "todos los amigos que me han ayudado a reorientar mi pensamiento y mi vida en los últimos años...dentro de la permanente crítica que debe distinguir a todo intelectual”22. En respuesta al Informe Rockefeller en un coloquio en París organizado por Josué de $\mathrm{Castro}^{23}$ hizo una crítica frontal a los puntos centrales de dicho informe:

"ante el reto de Rockefeller la vía propia de acción, ciencia y cultura es la única respuesta digna para una sociedad como la nuestra que merece sobrevivir en el mundo y que debe ser defendida",

Luego de llamar a la

Conversión a la izquierda de los grupos progresistas e insurgentes en los Estados Unidos...término a la política colonial de la OEA [especialmente frente a Cuba]...desarrollo de la autonomía cultural y científica; obtención de la independencia política y económica de la región. He aqui un programa de acción y una política general. El científico latinoamericano puede colaborar en esta tarea al promulgar e imponer reglas adecuadas para una ciencia nueva, rebelde

22 FALS BORDA, Orlando, Ciencia Propia y Colonialismo Intelectual.

${ }^{23}$ El evento fue sobre el "Informe Rockefeller y el Futuro de América Latina" y se realizó en

el Centre Internacional pour le Développement, Paris, diciembre de 1969. 
Las ciencias sociales y la invención del mundo

y comprometida con la reconstrucción social necesaria ... Es la tarea del momento la que parece de mayor trascendencia y envergadura, la que definirá el futuro de América Latina como el todo que ya es y que empieza a articularse. ${ }^{24}$

Al preguntarse por una "Sociología de la Liberación" profundiza escandalosamente estos planteamientos cuando señala:

La vía propia de la acción, ciencia y cultura ...incluye la formación de una ciencia nueva, subversiva y rebelde...frente a aquella que hemos aprendido en otras latitudes y que es la que hasta ahora ha fijado las reglas del juego cientifico, determinando los temas y dándoles prioridades, acumulando selectivamente los conceptos y desarrollando técnicas especiales, también selectivas para fines particulares.

Pero era consciente de la gravedad de estas afirmaciones cuando atribuía el surgimiento de esa ciencia nueva de las contradicciones de la sociedad, a que la academia se las quería evadir y casi que aludiendo de manera directa a sus colegas de la Universidad nacional, afirmaba con vehemencia:

Hace apenas unos pocos años no era posible hablar en esos términos, escribir sobre una disciplina comprometida ni mucho menos postular una ciencia rebelde y subversiva...las estructuras políticas, económicas, ideológicas y culturales sufren tensiones cada vez más fuertes y estas tensiones sacuden y cuartean las torres de marfil en que preferían acomodarse los cientificos. No hay ahora escapatoria posible y quienes salen de esas torres a respirar el aire del cambio tienen que hablar un nuevo lenguaje científico y sobre temas inusitados, quizá espeluznantes, aparentemente anticientificos, porque no encajan dentro del molde de lo normal que nos viene de otros territorios o de nuestros antiguos grupos de referencia.

Luego argumenta por qué una sociología de la Liberación:

Uno de esos campos nuevos para la sociología sería indudablemente, el de la liberación, es decir, la utilización del modelo científico para describir, analizar y aplicar el conocimiento para transformar la sociedad, trastocar la estructura de poder y de clases que condiciona esa transformación y poner en marcha todas las medidas conducentes a asegurar una satisfacción más amplia $y$ real del pueblo. ${ }^{25}$

Había roto Fals la frontera de la irreverencia y se había trasladado al campo de un macartizado anarquismo científico que rompía todos los cánones de la decencia de sus pares universitarios, descalificando hasta su lenguaje, no sin poca razón. Anticipaba la contradicción entre un saber académico paquidérmico, si bien erudito, pero casi inútil reivindicando la acción social que hoy muchos científicos sociales reclaman a la

\footnotetext{
${ }^{24}$ FALS BORDA, Orlando. (1976): Ciencia propia y colonialismo intelectual. Bogotá, Punta de Lanza, 4a ed, p. 20-21.

25 Óp. Cit., pp. 22- 23.
}

Rhela. Vol. 12. Año 2009, pp. $42-61$ 
universidad, desde los centros de pensamiento y ONG independientes que han aportado mucho a los debates y transformaciones necesarias en el campo de lo social. Anticipaba también Fals algo que hoy los teóricos de la ciencia reconocen: La llamada "ciencia modo2." ${ }^{26}$ De alguna forma los colegas que se quedaron en la universidad se aferraron al modelo disciplinar "modo1", monopolio de los pares, jerarquizada, sin muchos afanes de divulgación y con poca responsabilidad social. En tanto que el reclamo de Fals por una ciencia útil, inter y transdisciplinaria y aplicable a los problemas del desarrollo de América Latina, hoy tiene mucho sentido. Su propósito siempre fue el trabajo colectivo y su afán que el conocimiento fuera validado por las comunidades no solo científicas sino en conjunción con los sectores "estudiados", las comunidades objeto-sujeto. ${ }^{27}$

La Historia Popular y la Transformación Social: A partir de entonces radicaliza su crítica al capitalismo "subdesarrollado" e inicia la prueba de fuego para sus nuevas teorías: consolida la idea que intuitivamente venía desarrollando desde sus primeras obras: el conocimiento histórico debe ser el fundamento de las transformaciones sociales, pero no cualquier tipo de historia, una historia de carácter popular hecha por las propias comunidades como herramienta de apropiación de su realidad.

Es así inicia su obra histórica de largo aliento de investigación en el terreno: "La Historia Doble de la Costa" con su experimento bibliográfico y vanguardista: revolucionar hasta la forma de escribir, de manera doble, como lo reseña el investigador Gonzalo Cataño:

"Fals Borda quiso innovar no sólo en el método de investigación sino también, en el método de exposición. Como las vanguardias literarias de América Latina de hoy en día, que buscan destruir el relato mezclando los más diversos géneros y manifestaciones artísticas -música, pintura,

\footnotetext{
${ }^{26}$ Este concepto de los modos de hacer ciencia, surge el los 90: ver: GIBBONS, M., LIMOGES, C., NOWOTNY, H., SCHWARTZMAN, SCOTT, P. \& TROW, M., 1996, The New Production of Knowledge. The dynamics of Science and Research in Contemporary Societies. SAGE Publications, London. También: ZIMAN, J., (1996): «Is science loosing its objectivity?», Nature, 382:751-754.

27 Para aclarar la idea: "En el modo 1, la ciencia es mono disciplinaria y se realiza en organizaciones jerárquicas permanentes (universidades y centros de investigación) con el objetivo primario de avanzar en el conocimiento de la realidad. Sus metas son fijadas por los propios investigadores y sus productos son del dominio público y sólo se convierten en parte del corpus de una disciplina luego de un cuidadoso control por la comunidad de pares. La investigación del modo 2 es transdisciplinaria, sus ejecutores integran transitoriamente grupos no jerárquicos, que se constituyen ad hoc para resolver alguna demanda social y luego se disuelven, y la validación de sus resultados descansa en la aceptación social del producto más que en el juicio de los pares. En contraste con lo que sucede con el primer modo, los temas de investigación del segundo vienen dados por las razones que dan origen al grupo de trabajo... Quizá la diferencia más substancial entre ambos modos de crear conocimiento reside en que el tradicional concentra sus esfuerzos en la búsqueda de principios generales, mientras el nuevo quita el énfasis central de tal búsqueda y lo pone en la manipulación innovadora de lo ya conocido". Revista Ciencia Hoy. Buenos Aires Argentina, Vol. 7, No. 41, 1997. Leído 5-06-2009. http://www.cienciahoy.org.ar/hoy41/editorial.htm.
} 
Las ciencias sociales y la invención del mundo

poesía y prosa-, a fin de re-saltar las sensaciones de ritmo, espacio y tiempo, Fals Borda quiere superar el tradicional informe sociológico. Para ello ha adoptado una exposición a dos voces: una, la de la página izquierda, anecdótico, coloquial y descriptiva, y la otra, la de la derecha, «seria», documental, teórica, conceptual y metodológica. La primera es sostenida generalmente por personajes vivos con los cuales el autor está dialogando, mientras que la segunda presenta las fuentes y las explicaciones de los procesos sociales que son objeto del cuento y de la anécdota. Esto produce en el lector la impresión de un contrapunto, donde las voces del presente y del pasado establecen un diálogo que nunca parece acabar. Y como en los textos de mediados de la década del setenta, la profusión de fotografias, dibujos y mapas que ilustran el cuarteto, recrean una vez más la fuerza de una cultura que a fines del siglo XX se niega a desaparecer ante la impetuosidad del mundo urbanoindustrial. $^{28}$

Así produce los cuatro tomos de esta importante obra publicada entre 1979 y 1986 donde cristaliza la idea de una historia contestataria, original y al servicio de la causa popular.

La "Historia Doble" se convirtió en una forma innovadora de investigar y de contar la Historia, reconociendo la cultura y aceptando el saber popular, lo cual lo distanciaba cada vez más de los saberes académicos y lo convertía más, según algunos, en "activista" que en científico. ${ }^{29}$ Era la aplicación en el campo de la disciplina Histórica de su idea de una ciencia útil y al servicio del pueblo. Orlando Fals fue pionero en su tiempo de una visión más holística, diríamos hoy. Se alejó intencionalmente de la neutralidad valorativa y según algunos, se acercaba no solo al socialismo sino al anarquismo. Pero más que al anarquismo o al socialismo marxista, Fals se inscribió en esa época de su vida, con María Cristina Salazar, en una especie de existencialismo, cercano a Jean Paul Sartre y a Simone de Beauvoir, como lo ratifican en sendas entrevistas, etapa que desarrollaremos en una segunda entrega. ${ }^{30}$

\section{CONCLUSIONES}

Es no solamente por la creación de la primera Facultad de Sociología sino por su obra intelectual que Orlando Fals es uno de los grandes de las ciencias sociales en Colombia. La tesis que hemos desarrollado es que Fals es uno de los fundadores de la

\footnotetext{
${ }^{28}$ Cataño, G. op.cit., p. 90

29 Por ejemplo, el Historiador Mauricio Archila se tomó el trabajo de reseñar todos los tomos de la Historia doble de La Costa, y en estos textos de manera muy crítica señala los aciertos historiográficos y crítica con fundamento muchos de sus planteamientos metodológicos de la IAP, sin dejar de valorar sus aportes. Al respecto Ver: Boletín Cultural y Bibliográfico. Número 2, Volumen XXI, 1984; Boletín Cultural y Bibliográfico. Número7, Volumen XXIII, 1986.

${ }^{30}$ SALAZAR, María C. (2006): Los Esclavos invisibles, Autoritarismo, Explotación y Derechos Humanos de los Niños en América Latina. Tunja, Uptc, p 161 ss.
} 
idea del Tercer Mundo desde la sociología y que su obra, bastante extensa y polémica por cierto, constituyó una ruptura con los paradigmas positivistas dominantes. De las cinco etapas en que hemos caracterizado su pensamiento, hemos desarrollado las dos primeras para demostrar las rupturas que su obra planteó frente a la sociología establecida. Describimos en la primera época sus trabajos fundadores de una corriente de estudios agrarios. La segunda etapa de la obra de Orlando Fals Borda es sin duda pionera de una nueva sociología latinoamericana, antecesora de lo que se ha dado en llamar "la ciencia Modo 2". Conclusiones provisionales advirtiendo que esta es la primara parte de una reflexión más amplia.

\section{FUENTES}

Entrevista al Dr. Orlando Fals Borda (2002): realizada por Javier Guerrero para la Revista Pensamiento y Acción. Bogotá, 3 de agosto.

FALS BORDA, Orlando. (1959): La teoría y la realidad del cambio socio-cultural en un sistema social rural. Bogotá, Facultad de Sociología, Monografía $\mathrm{N}^{\circ} 2$.

. (1961): Acción comunal en una vereda colombiana. Bogotá. Facultad de Sociología. Universidad Nacional. Monografía $\mathrm{N}^{\circ} 4$.

(1961): Peasant Society in the Colombian Andes: A sociological study of Saucio, Gainesville, University of Florida Press. Edición castellana con el título de Campesinos de los Andes, Bogotá, Universidad Nacional-Facultad de Sociología.

, GUZMÁN, Germán, UMAÑA LUNA, Eduardo. (1962): La violencia en Colombia. Bogotá. Tercer Mundo-Universidad Nacional. (Reimpresión en Bogotá, Editorial Iqueima, 1963).T. 21964 XXI Editores.

(1968): Revoluciones inconclusas en América Latina 1809-1968. México, Siglo

. (1969)“La crisis social y la orientación sociológica: una réplica”, en Revista Aportes 13. ed, p. $20-21$

(1976): Ciencia propia y colonialismo intelectual. Bogotá, Punta de Lanza, 4a . (1976): Ciencia propia y colonialismo intelectual. Bogotá, Punta de Lanza, 4a ed.

(1996): Región e Historia: elementos sobre ordenamiento y equilibrio regional en Colombia. Bogotá, TM Editores.

. (2000): Acción y espacio. Autonomía en la Nueva República. Bogotá. Instituto de Estudios Políticos. Universidad Nacional. Tercer Mundo Editores.

. (2006): El Hombre y la Tierra en Boyacá. Bases sociológicas e históricas para una Reforma Agraria. Tunja. UPTC. Universidad Pedagógica y Tecnológica de Colombia.

\section{SELECCIÓN BIBLIOGRÁFICA}

ARCHILA, Mauricio. (1984):“Creamos: cachacos violentos, costeños pachangosos”. Reseña sobre el tomo II del libro Historia doble de la Costa, de Orlando Fals Borda, en Boletín Cultural y Bibliográfico. Número 2, Volumen XXI.

. (1984) "Los hombres-hicoteas y la resistencia popular". Reseña de Mauricio Archila sobre el texto Resistencia en San Jorge, perteneciente al tomo III de la Historia doble de la Costa, de Orlando Fals Borda. . En: Boletín Cultural y Bibliográfico. Número 2, Volumen XXI. 
Las ciencias sociales y la invención del mundo

(1986): “A Nobleza Comprada le sale su Hombre Caimán”. Reseña de Mauricio Archila del libro de Orlando Fals Borda. Historia doble de la Costa, T. 1, en Boletín Cultural y Bibliográfico. Número7, Volumen XXIII.

. (1986): Retorno a la investigación social. Reseña de Retorno a la tierra (Historia doble de la Costa, t. IV) de Orlando Fals Borda, Carlos Valencia Editores, Bogotá, en Boletín Cultural y Bibliográfico. Número7, Volumen XXIII.

BURLATSKI, F., dir.(1982): Materialismo histórico. Moscú. Editorial Progreso.

CATAÑO, Gonzalo y Orlando Fals Borda. (2008): "sociólogo del compromiso", en Revista de Economía Institucional, vol. 10, $n .{ }^{\circ} 19$, segundo semestre.

GIBBONS, M., LIMOGES, C., NOWOTNY, H., SCHWARTZMAN, SCOTT, P. \& TROW, M.,(1996):The New Production of Knowledge. The dynamics of Science and Research in Contemporary Societies. SAGE Publications, London,

GOULDNER, Alvin W. (1979): La Crisis de la Sociología Occidental. Buenos Aires Editorial Amorrortu.

GUERRERO, Javier. (2007): Los Años del Olvido: Boyacá y los Orígenes de la Violencia. Tunja. UPTC. $2^{\mathrm{a}}$ ed.

REYES, Alejandro. (2009): Guerreros y campesinos. El despojo de la tierra en Colombia. Bogotá. Editorial Norma.

SALAZAR, María C. (2006): Los Esclavos invisibles, Autoritarismo, Explotación y Derechos Humanos de los Niños en América Latina. Tunja. UPTC.

SÁNCHEZ GÓMEZ, Gonzalo.”El compromiso social y político de los intelectuales”, en Revista Pensamiento y Acción. No. 10 Revista Internacional de la Universidad Pedagógica y Tecnológica de Colombia.

. (1999): Reseña de "La Violencia en Colombia", en Revista Credencial Historia No. 110. Bogotá.

ZIMAN, J. (1996):’Is science loosing its objectivity?” In: Nature Reviw, 382:751-754.

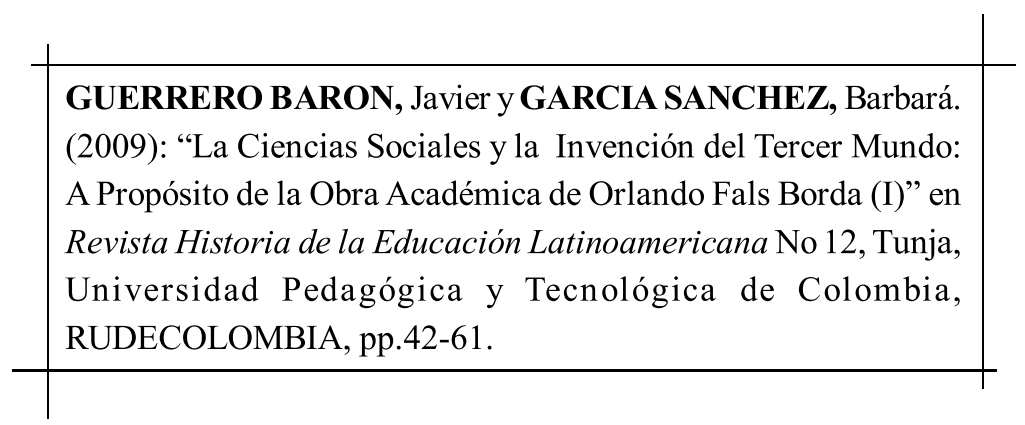

Rhela. Vol. 12. Año 2009, pp. 42 - 61 